\title{
SCHRIFTENVERZEICHNIS VON CZESŁAW KAROLAK
}

\author{
(Stand: Januar 2017)
}

\section{Monographien - editorische Schriften — akademische Lehrwerke}

(1986) Die Poetik des Vorurteils. Untersuchungen zum Fremdstereotyp im westdeutschen Roman der fünfziger Jahre (Seria Filologia Germańska, 26). Poznań: Wydaw. Naukowe UAM, 252 S.

(1989) Dem Frieden entgegen. Ein Lesebuch mit 100 Texten aus fünf Jahrhunderten. Hrsg. vom Internationalen Deutschlehrerverband (Co-Ed.: R. Zellweger, E. Batley, H.-W. Grüninger, L. Richter, J. Weisz). Leipzig: Enzyklopädie; München: Langenscheidt. $176 \mathrm{~S}$.

(1993) Niemcy o sobie. Naród - państwo - „charakter narodowy” w oczach intelektualistów niemieckich. Wybrał i wstępem opatrzył... Poznań: Instytut Zachodni. $332 \mathrm{~S}$.

(1997) Kulturatlas Polen (multimediale Ausgabe) (Mitverf.: E. Aimée, J. Tatarska, N. H. Weber et al.). Gotha: Klett-Perthes.

(1997) Kulturatlas Musik: Polen (Mitverf.: J. Tatarska) Gotha: Klett-Perthes. 28 S. + Audio-CD.

(1998) Zum Beispiel Sachsen-Anhalt. Deutsch mit authentischen Hörtexten (Mitverf. u. Mithrsg.: M. Grzywacz, K.-D. Hansch, G. Hartung, P. Jankowiak \& V. Wein). 2 Bde. Warszawa: Wydaw. Szkolne i Pedagogiczne. 90, 71 S.

(1999) Dydaktyka literatury wobec potrzeb nauki języka w warunkach obcokulturowych. Poznań: Wydaw. Naukowe UAM. 184 S.

(2000) Cenzura $w$ Niemczech $w$ XX wieku. Studia, analizy, dokumenty (Poznańska Biblioteka Niemiecka, 9). Poznań: Wydaw. Poznańskie. 475 S.

(2007/2015) Dzieje kultury niemieckiej. (1./2. Aufl.). (Mitverf.: H. Orłowski \& W. Kunicki). Warszawa: PWN. 572/606 S.

(2007) „,Schuhnummer oder Leben“: Beiträge zum kinder- und jugendliterarischen Schrifttum. Hrsg. von E. Białek und Cz. Karolak. Dresden: Neisse; Wrocław: Atut. $429 \mathrm{~S}$.

(2009/2010) Quellentexte zur deutschsprachigen Literaturgeschichte. (Co-Ed.: H. Orłowski; Hrsg. der einz. Bde.: I - K. Dzikowska, II - R. Dziergwa, III - M. Wojtczak, IV - I. Sellmer, V - H. Orłowski, S. Piontek, E. Pytel, B. Rowińska-Januszewska \& J. Krauze, VI - St. H. Kaszyński). 6 Bde. Poznań: Wydaw. Poznańskie. 2205 S. 
(2014) Ungeduld der Erkenntnis. Eine klischeewidrige Festschrift für Hubert Orłowski, hrsg. von W. Bialik, Cz. Karolak \& M. Wojtczak. Frankfurt a. M.: Lang. $336 \mathrm{~S}$.

\section{Beiträge in Zeitschriften / Sammelbänden}

(1968) Konflikt ojciec-syn jako autobiograficzny motyw w twórczości Franza Kafki. In: Biuletyn Kót Naukowych UAM. Referaty zgtoszone na uczelnianq sesje „Kota naukowe o sobie”, 18.-19.05.1968 (S. 39-47). Poznań: Rada Uczelniana ZSP.

(1976) $\mathrm{Zu}$ den Kategorien des Engagements in der Literatur der BRD der 60er Jahre. Kwartalnik Neofilologiczny, 4, 425-431.

(1978) I Ogólnopolska Olimpiada Języka Niemieckiego (Mitverf.: M. Drażyńska-Deja \& W. Pfeiffer). Języki Obce w Szkole, 4, 219-222.

(1979) Autothematische Motive in der Lyrik der DDR. Studia Germanica Posnaniensia, VIII, 135-142.

(1981) Das metaliterarische Selbstverständnis westdeutscher Autoren. Germanistische Dissertationen in Kurzfassung (Jahrbuch für Internationale Germanistik, Reihe B, Bd. 6, Nr. 233). Bern: Lang. 6 S.

(1981) Zur Sprachreflexion in der Lyrik der DDR. In W. Steinberg (Hrsg.), Funktion der Sprachgestaltung im literarischen Text (Kongreß- und Tagungsberichte der Martin-Luther-Universität Halle-Wittenberg. Wissenschaftliche Beiträge, 52), S. 134-141.

(1982) Der zukunftspolitische westdeutsche Roman. Ansätze zur Konstituierung und kritischen Validierung des Begriffs , autoritäre Geschichtsauffassung ‘. Studia Germanica Posnaniensia, X, 3-27.

(1982) Chorągwie przestały łopotać. Nowe oblicze liryki NRD lat siedemdziesiątych. In H. Orłowski (red.), Współczesna literatura NRD. Szkice (S. 60-70). Poznań: Wydaw. Poznańskie.

(1982) Na coraz szerszym marginesie twórczości. Pozaliterackie wypowiedzi pisarzy NRD. In H. Orłowski (red.), Wspótczesna literatura NRD. Szkice (S. 124-142). Poznań: Wydaw. Poznańskie.

(1982) Literatura RFN z perspektywy lat osiemdziesiątych. Nurt, 7, 19-21.

(1983) Deutschsprachige Literatur in den neuesten polnischen Darstellungen. Ein Überblick über die Problemsituation der Jahre 1979-82. Studia Germanica Posnaniensia, XII, 131-139.

(1983) Socjologia stereotypu a krytyka świadomości potocznej w literaturze RFN. Przegląd Zachodni, 3, 63-83.

(1983) Deutsch mal anders - Entwurf einer Lehrbuchkonzeption (Mitverf: M. Drażyńska-Deja \& W. Pfeiffer). Glottodidactica, XVI, S. 69-86. 
(1985) Fantastyka polityczna w powieści zachodnioniemieckiej. In B. Andrzejewski (red.), Jednostka - społeczeństwo - państwo. Z filozoficznej refleksji nad zagadnieniem władzy (S. 123-132). Poznań: Wydaw. UAM.

(1986) Franz Kafka: „Proces” czyli rebelia bezsilności. Nurt, 5, 10-13.

(1987) Die andere Seite der Barrikade. Der spanische Bürgerkrieg aus der Perspektive der Literatur im Dritten Reich. Germanica Wratislaviensia, LXXVII, 50-56.

(1989) Zur Geschichte der Germanistik an der Adam-Mickiewicz-Universität Poznań. Skamandros, 355-368.

(1990) Treści krajoznawcze w nauczaniu języka niemieckiego w Polsce. Neofilo$\log , 2,65-70$.

(1990) Deutsche Literatur nach dem Dritten Reich. Die fünfziger Jahre im „toten Winkel“ der Geschichte. Studia Germanica Posnaniensia, XIV, 81-104.

(1990) Feindbilder und Vorurteile in den Ost-West-Beziehungen. In K.-D. Mende \& H.-F. Rathenow (Hrsg.), Feindbilder und Vorurteile im Ost-West-Verhältnis. Ergebnisse des 4. Internationalen Workshops zur Friedenspädagogik in Berlin (West) (S. 23-28). Berlin: Univ.-Bibl. der TU.

(1991) Zum Problem kommunikativer Didaktisierungsmöglichkeiten literarischer Texte im Fremdsprachenunterricht. Studia Germanica Posnaniensia, XVII/XVIII, 181-187.

(1991) Zur Geschichte der Abteilung für Methodik und Didaktik DaF. Studia Germanica Posnaniensia, XVII/XVIII, 31-34.

(1992) Deutschlehrwerke in Polen vor kulturrelativierenden Aufgaben. Lingua ac communitas, 1, 119-127.

(1992) Między wizją zagłady a ekologiczną idyllą. Problematyka ekologiczna w powojennej niemieckojęzycznej powieści fantastycznej. In B. Andrzejewski (red.), Ochrona środowiska w refleksji humanistycznej (S. 97-103). Poznań: Wydaw. PTPN.

(1992) Na czym polega odmienność koncepcji podręcznika „Deutsch mal anders?”. Neofilolog, 5, 54-58.

(1993) Germanistik und Deutschunterricht in Polen - Möglichkeiten curricularer Planung, dargestellt am Beispiel der Universität Poznań (Mitverf.: P. Danielewicz). Deutsch-Polnisches Jahrbuch der Germanistik (DAAD), 169-177.

(1994) Möglichkeiten curricularer Planung im Germanistikstudium in Polen. Fragen der Deutschlehrerausbildung. In DAAD (Hrsg.), Dokumentation der Tagungsbeiträge / Germanistentreffen Bundesrepublik Deutschland - Polen: 26.9. - 30.9.1993, (Red.: Werner Roggausch). (S. 313-318) Bonn: DAAD.

(1994) Das System der Zensur und seine Auswirkungen auf die Literalität. In H. Günther \& O. Ludwig (Hrsg.), Schrift und Schriftlichkeit. Ein interdisziplinäres Handbuch internationaler Forschung (S. 893-898). Berlin: de Gruyter. 
(1995) Unbewältigte Zukunft. Kriegs- und Fortschrittsvisionen in der westdeutschen Science-fiction-Literatur der 50er Jahre. In B. Spies (Hrsg.), Ideologie und Utopie in der deutschen Literatur der Neuzeit (S. 144-150). Würzburg: Königshausen \& Neumann.

(1995) Verschwenderisch, trunksüchtig und bestechlich? Deutsche in den Augen polnischer Schüler und Studenten. Convivium: germanistisches Jahrbuch Polen (DAAD), 295-301.

(1995) Die Wortschatzvermittlung aus der Perspektive der Lehrwerkgestaltung betrachtet. In J. Iluk (Hrsg.), Aspekte der Wortschatzbeschreibung (S. 33-40). Katowice: Wydaw. UŚ.

(1995) Przekaz słownictwa a koncepcja podręcznika do nauki języka obcego. Neofilolog, 10, 46-52.

(1996) [17 Biogramme]. In M. Zybura (red.), Pisarze niemieckojęzyczni XX wieku. Leksykon encyklopedyczny PWN (S.: 9 f., 43, 63-65, 99, 103, 115, 142 f., 183 f., 186, 214, 251 f., 276, 305, 316). Warszawa: Wydaw. Naukowe PWN.

(1996) [45 Biogramme]. In St. Sierpkowski (red.) \& St. Żerka (współpr.), Leksykon Historii Powszechnej 1900-1945 (S. 1, 20, 34, 118, 122, 151 f., 161, 164, 197, 206, 216, 219, 261, 298 f., 313, 346, 368 f., 373, 443, 497). Poznań: Wydaw. Naukowe UAM.

(1996) Literaturverstehen und Textdidaktik in fremdsprachenspezifischer Perspektive. Convivium: germanistisches Jahrbuch Polen (DAAD), 345-358.

(1996) Postawy pisarzy w III Rzeszy a ich powojenna autorefleksja. In M. Jabłoński \& J. Tatarska (red.), Muzyka i totalitaryzm (S. 9-17). Poznań: Ars Nova.

(1997) [102 Biogramme]. In H. Orłowski, R. Dziergwa, J. Kałążny, Cz. Karolak \& E. Połczyńska: Stownik twórców kultury niemieckojęzycznej. Poznań: Wydaw. Poznańskie.

(1998) Literaturverstehen und Textdidaktik in fremdsprachenspezifischer Perspektive. In H. Fischer (Hrsg.), Ist die Germanistik zeitgenössisch? (S. 53-68). Frankfurt a. M.: Lang.

(1998) Dydaktyka tekstu literackiego w świetle potrzeb nauki języka w warunkach obcokulturowych. Glottodidactica, XXVI, 137-150.

(1999) Nowe cykle podręczników do nauki języka niemieckiego (Mitverf.: M. Drażyńska-Deja \& W. Pfeiffer). Języki Obce w Szkole, 1, 53-58.

(1999) Deutsch als Fremdsprache in der Bundesrepublik Deutschland. Zur Diskussion um die Situation des Faches - Bemerkungen aus literaturdidaktischer Sicht. Convivium: germanistisches Jahrbuch Polen (DAAD), 309-323.

(1999) Problemy odbioru tekstu literackiego w warunkach obcokulturowych. Lingua ac communitas, 9, 139-151.

(1999) [Thematische Beiträge und Biogramme]. In: Niemcy Wspótczesne. Zarys encyklopedyczny (S. 13 f., 21, 42 f., 52 f., 69, 110 f., 116 f., 158, 195 ff., 251 f., 267 f., 305-314, 326 ff., 343, 374-379, 411, 467 f., 555, 561, 573, 586, 637, 648 f., 773, 776). Poznań: Instytut Zachodni. 
(2001) Das Suchbild des Zensors. Methodologische Probleme einer literaturwissenschaftlichen Zensurforschung. In Chr. Grimm, I. Nagelschmidt \& L. Stockinger (Hrsg.), Mannigfaltigkeit der Richtungen (Literatur und Kultur. Reihe A: Dialoge und Kolloquien; Bd. 2.) (S. 247-260). Leipzig: Universitätsverl.

(2002) Digitale Literatur und ihre Auswirkungen auf den Leseprozess. Convivium: germanistisches Jahrbuch Polen (DAAD), 129-140.

(2003) „In die Geschichte hinabgraben...“ Ina Seidels erzählerische Selbstdarstellung. In I. Sellmer (Hrsg.), Die biographische Illusion im 20. Jahrhundert. (Auto-)Biographien unter Legitimierungszwang (S. 73-80). Frankfurt a. M.: Lang.

(2003) Zur integrierenden Funktion von Literatur im Verstehensprozess fremder Kultur. Kwartalnik Neofilologiczny, 165-170.

(2004) Zur integrierenden Funktion von Literatur im Verstehensprozess fremder Kultur. In C. Badstübner-Kizik, R. Rozalowska-Żądło \& A. Uniszewska (Hrsg.), Sprachen lehren, Sprachen lernen (S. 231-239). Gdańsk: Wydaw. UG.

(2007) Literaturdidaktik und Kulturkompetenz. Curriculare Überlegungen. In E. Białek \& Cz. Karolak (Hrsg.), ,,Schuhnummer oder Leben “. Beiträge zur Literaturdidaktik und zum kinder- und jugendliterarischen Schrifttum (S. 33-41). Dresden: Neisse; Wrocław: Atut.

(2008) Zur Zensurgeschichte im Schatten politischer „Religionen“. Die Mittel zur Überwachung und Unterwanderung des kulturellen Lebens in Deutschland im 20. Jahrhundert. In K. Myczko, B. Skowronek \& W. Zabrocki (red.), Perspektywy glottodydaktyki i językoznawstwa (S. 345-358). Poznań: Wydaw. Naukowe UAM.

(2011) Jakob Michael Reinhold Lenz: „Philosophische Vorlesungen für empfindsame Seelen"- ein adoleszenter Moralkatechismus des Sturm und Drang? In C. Gansel \& P. Zimniak (Hrsg.), Zwischenzeit, Grenzüberschreitung, Aufstörung. Bilder von Adoleszenz in der deutschsprachigen Literatur (S. 225-235). Heidelberg: Winter.

(2011) Der Jugendroman im Zeitalter der Neuen Medien. Literarische Wertung aus der Sicht adoleszenter Leser am Beispiel des Romans „Einundzwanzigster Juli“ von Anne C. VoorhoeveIn. In C. Gansel \& P. Zimniak (Hrsg.), Zwischenzeit, Grenzüberschreitung, Aufstörung. Bilder von Adoleszenz in der deutschsprachigen Literatur (S. 383-392). Heidelberg: Winter.

(2011) Widerstand gegen Zensur im Dritten Reich und seine Reflexion nach 1945. In M. Domaradzki, E. Kulczycki \& M. Wendland (red.): Język, rozumienie, komunikacja (Pisma Filozoficzne, CXXI). (S. 109-115). Poznań: Wydaw. Naukowe Instytutu Filozofii UAM.

(2012) Der interaktive Leser. Inhaltliche und technisch-ästhetische Aspekte des Phänomens ,Digitale Literatur‘. In A. Kochanowska-Nieborak \& E. Pło- 
mińska-Krawiec (Hrsg.), Literatur und Literaturwissenschaft im Zeichen der Globalisierung (S. 291-297). Frankfurt a. M.: Lang.

(2012) Von der „Sendebühne“ zum Hörspiel. Zu einem „,neuen“ literarischen Genre nach 1945. In K. Grzywka (red.), Kultura, literatura, język. Pogranicza komparatystyki. Prace ofiarowane Profesorowi Lechowi Kolago w 70. Rocznice urodzin, t. I (S. 769-778). Warszawa: Instytut Germanistyki UW.

(2012) Nichtlineare Textrezeption am Beispiel des Phänomens ,Digitale Literatur‘. In F. Grucza (Hrsg.), Vielheit und Einheit der Germanistik weltweit, Bd. 16 (S. 205-210). Frankfurt a. M.: Lang.

(2013) Politische faits accomplis im Konjunktiv? Nachdenken über , ungeschehene Geschichte" in der deutschen und polnischen Literatur. In H.-W. Heister \& B. Spies (Hrsg.), Mimesis, Mimikry, Simulatio. Tarnung und Aufdeckung in den Künsten vom 16. bis zum 21. Jahrhundert. Festschrift für Erwin Rotermund (S. 217-227). Berlin: Weidle.

(2013) Pamięć bibliotek. Zadania i wyzwania dla bibliotek i organizacji zbiorów w Niemczech po 1990 roku. In St. Puppel \& T. Tomaszkiewicz (red.), Scripta Manent - res nova (S. 115-126). Poznań: Wydaw. Naukowe UAM.

(2014) Digitale Wiedergeburten für den Tempel der Weisheit. Bibliotheks- und museale Sammlungen im Netz als Antwort auf die Herausforderungen der Informationsgesellschaft. In W. Bialik, Cz. Karolak \& M. Wojtczak (Hrsg.), Ungeduld der Erkenntnis. Eine klischeewidrige Festschrift für Hubert Ortowski (S.109-124). Frankfurt a. M.: Lang.

(2014) Polityczne fakty dokonane $\mathrm{w}$ trybie przypuszczającym? Rozmyślania o „historii niezaistniałej” w literaturze polskiej i niemieckiej. In M. Düring \& K. Trybuś (Hrsg.), Polen und Deutsche in Europa. Beiträge zur internationalen Konferenz, 25. und 26. Oktober 2012, Kiel. Polacy i Niemcy w Europie: tom podsumowujący konferencję międzynarodowa, 25 i 26 października 2012, Kilonia (S. 249-258). Frankfurt a. M.: Lang.

(2015) Zwischen Gleichnishaftigkeit und Realismus. Elemente kafkaesker Komik in Siegfried Lenz’ Kurzroman „Landesbühne“. In C. Jakobi \& Chr. Waldschmidt (Hrsg.), Witz und Wirklichkeit. Komik als Form ästhetischer Weltaneignung (S. 469-480). Bielefeld: Transcript.

(2016) Innere Emigration im Spannungsfeld disjunktiver Leseerwartungen. Der lange Schatten der (Selbst-)Zensur im Dritten Reich. In M. Gołaszewski, M. Kardach \& L. Krenzlin (Hrsg.), Zwischen, Innerer Emigration ' und Exil. Deutschsprachige Schriftsteller 1933-1945 (S. 129-139). Berlin: de Gruyter.

(2016) „Emigracja wewnętrzna“ wobec wykluczających się oczekiwań czytelniczych. Długi cień (auto-)cenzury w III Rzeszy. In H. Orłowski (Hrsg.), Emigracja wewnętrzna (Poznańska Biblioteka Niemiecka, 43). (S. 609-621). Poznań: Wydawnictwo Nauka i Innowacje. 


\section{Besprechungen / Rezensionen}

(1977) Biografia jako współautorstwo? [A. Rogalski (1975). Tomasz Mann. Dzieje rozwoju osobowości twórczej. Warszawa: Pax]. Nurt, 2, 33-34.

(1978) Polska w poezji NRD [(1978) Przyblizenia. Poeci Niemieckiej Republiki Demokratycznej o Polsce. Wybór, przedmowa i noty biograficzne St. H. Kaszyński. Poznań: Wydaw. Poznańskie]. Nurt, 11, 25.

(1979) [H. Wysling (1974). Zur Situation des Schriftstellers in der Gegenwart. Bern: Francke]. Studia Germanica Posnaniensia, VII, 208-209.

(1980) Jeszcze o 30-leciu literatury NRD [N. Honsza (red.). (1979). 30 Jahre DDR-Literatur. (Acta Univ. Wratislaviensis, 498). Wrocław; Studia Germanica Posnaniensia, VIII. Poznań]. Nurt, 6, 23.

(1983) Zbliżenie i dystans [M. Diersch \& H. Orłowski (1983). Annäherung und Distanz. DDR-Literatur in der polnischen Literaturkritik. Halle: Mitteldeutscher Verl.]. Nurt, 9, 35-36.

(1985) Współczesna literatura Austrii i Szwajcarii [K. Koczy \& K. Skrzypczak (red.).

(1984) Interpretationen und Polemiken. Österreichische und schweizerische Literatur der Gegenwart. Katowice: UŚ]. Nurt, 6, 21.

(1985) [U. Förster (1983). Landeskunde und Entwicklung sprachlichen Könnens. Leipzig: Enzyklopädie]. Glottodidactica, XVII, 132-133.

(1986) Poezja Ericha Arendta [E. Arendt (1985), Źdźbło ognia. Wybór i przekład St. H. Kaszynski i E. Wachowiak. Poznań: Wydaw. Poznańskie]. Nurt, 4, 38-39.

(1987) [W. Bialik (1987). Johannes Mario Simmel oder der unvermeidliche Erfolg. Poznań: Wydaw. Naukowe UAM]. Przeglad Zachodni, 4, 192-193.

(1992) [J. Douvitsas-Gamst, E. Xanthos \& S. Xanthos-Kretzschmer (1989). Das Deutschmobil. München: Klett] (Mitverf.: M. Gąsiorek). IDV-Rundbrief, 49, 47-48.

(1992) [H. Orłowski \& G. Hartung (Hrsg.). (1992). Traditionen und Traditionssuche des deutschen Faschismus. 4. Protokollband (Seria filologia germańska, 36). Poznań: Wydaw. Naukowe UAM]. Przeglad Zachodni, 4, 226-229.

(1993) [J. Iluk (1991). Übungen zur Rektion deutscher Verben. Skrypty Uniwersytetu Ślaskiego, 452. Katowice: UŚ]. Glottodidactica, 21, 193-194.

(1993) [H. Orłowski \& G. Hartung (Hrsg.). (1992). Traditionen und Traditionssuche des deutschen Faschismus. 4. Protokollband (Seria filologia germańska, 36). Poznań: Wydaw. Naukowe UAM]. Polish Western Affairs, XXXIV, 149-152.

(1997) [J. Walther (1996). Sicherungsbereich Literatur. Schriftsteller und Staatssicherheit in der Deutschen Demokratischen Republik. Berlin: Links]. Convivium: germanistisches Jahrbuch Polen (DAAD), 475-478.

(1997) [N. Elias (1996): Rozważania o Niemcach. Zmaganie o władzę a habitus narodowy $i$ jego przemiany $w$ XIX $i$ XX $w$. Poznańska Biblioteka Niemiecka, 
pod red. H. Orłowskiego i Chr. Kleßmanna. Poznań: Wydaw. Poznańskie]. Przeglad Zachodni, 2, 229-231.

(1998) [L. Żyliński (1997). Heinrich Bölls Poetik der Zeitgenossenschaft. Toruń: Wydaw. UMK]. Przeglad Zachodni, 1, 175-177.

(2000) [H. Ehrke-Rotermund \& E. Rotermund (1999). Zwischenreiche und Gegenwelten. Texte und Vorstudien zur „Verdeckten Schreibweise im Dritten Reich“. München: Fink]. Orbis Linguarum, 15, 225-227.

(2001) [K. Sauerland (2000). Dreißig Silberlinge. Denunziation: Gegenwart und Geschichte. Berlin: Volk und Welt]. Convivium: germanistisches Jahrbuch Polen (DAAD), 447-448.

(2005) [I. Surynt (2004). Das ,ferne“, , unheimliche“ Land. Gustav Freytags Polen. Dresden: Thelem bei w.e.b.]. Orbis Linguarum, 28, 455-459.

(2006) [W. Grözinger (2004). Panorama des internationalen Gegenwartsromans. Gesammelte „Hochland"-Kritiken 1952-1965. Hrsg. von E. Rotermund und H. Ehrke-Rotermund. Paderborn: Schöningh]. Orbis Linguarum, 30, 447-449.

(2011) [Geschichtsverein des Kreises Euskirchen e. V. (Hrsg.). (2010). Simplicius und die Seinen. Über den Schriftsteller Heinz Küpper. Texte aus dem Nachlass, Abhandlungen, Essays. Bearbeitet von A. Erlinghagen. Weilerswist: Liebe \& Pabst]. Studia Germanica Posnaniensia, 32, 187-190.

\section{Übersetzungen}

Przybyszewska, St. (1978/1983). Listy [Briefe]. Bd. 1/2. Wydał i wstępem opatrzył T. Lewandowski. Gdańsk: Wydaw. Morskie. XXXIII, 678/XII, 639 S.

Tuschel, K.-H. (1983). Zimne słońce [Kalte Sonne. Erzählung]. In: Niemoc. Antologia opowiadań science fiction pisarzy Niemieckiej Republiki Demokratycznej. Wybór i posłowie H. Orłowski, wstęp G. Jäckel (S. 147-190). Poznań: Wydaw. Poznańskie.

Branstner, G. (1983). Kuracja wbrew woli [Die Kur wider Willen. Erzählung]. In: Niemoc. Antologia opowiadań science fiction pisarzy Niemieckiej Republiki Demokratycznej. Wybór i posłowie H. Orłowski, wstęp G. Jäckel (S. 388-390). Poznań: Wydaw. Poznańskie.

Braun, G. (1983). Powrót Jonatana [Jonatans Rückkehr. Erzählung]. In: Niemoc. Antologia opowiadań science fiction pisarzy Niemieckiej Republiki Demokratycznej. Wybór i posłowie H. Orłowski, wstęp G. Jäckel (S. 299-321). Poznań: Wydaw. Poznańskie.

Güntzel, S. G. (1983), Nic tylko kłopot z personelem [Nichts als Ärger mit dem Personal. Erzählung]. In: Niemoc. Antologia opowiadań science fiction pisarzy Niemieckiej Republiki Demokratycznej. Wybór i posłowie H. Orłowski, wstęp G. Jäckel (S. 402-410). Poznań: Wydaw. Poznańskie. 
Hildesheimer, W. (1983). Większy zakup [Eine größere Anschaffung. Erzählung]. Nurt, 1, 33. Ersch. auch in: Karolak (1999), S. 175-176.

Okopenko. A. (1983) Mój pierwszy zawał [Mein erster Herzinfarkt. Erzählung]. Nurt, 3, 36.

Lind, J. (1985) Podróż do kresu nocy [Reise durch die Nacht. Erzählung]. Nurt, 4, 32-34. Erschienen auch in: 1) (1990) Spotkanie poza czasem. Antologia fantastycznej noweli austriackiej. Wybór i przedmowa St. Kaszyński, S. 256-261. Poznań: Wydaw. Poznańskie. 2) Karolak (1999), S. 171-174.

Strauß, B. (1999). Dedykacja. Opowiadanie [Die Widmung. Eine Erzählung]. In: Karolak (1999), S. 153-155.

Daiber, H. (1999). Jako zapisane jest [Es steht geschrieben. Erzählung]. In: Karolak (1999) , S. 156-157.

Böll, H. (1999). Przy moście [An der Brücke/Meine ungezählte Geliebte. Erzählung]. In: Karolak (1999), S. 158-160.

Fichte, H. (1999). Podwójna anegdota [Doppelanekdote. Erzählung]. In: Karolak (1999), S. 162-163.

Bichsel, P. (1999), Pozdrowienia od wuja Jodoka [Onkel Jodok läßt grüßen. Erzählung]. In: Karolak (1999), S. 165-167.

Otto, U. (2000). Cenzura Literatury. Rozważania teoretyczne w oparciu o teorię Vilfredo Pareto [Theoretische Betrachtung der literarischen Zensur in Anlehnung an Gedanken Vilfredo Paretos]. In: Karolak (2000), S. 434-454

\section{Sprachlehrwerke}

(1979-2001) Deutsch mal anders / Deutsch mal anders neu / Deutsch global / Deutsch International / Kontakte /Deutsch ist ,, in “ (Mitverfasser: M. Drażyńska-Deja \& W. Pfeiffer). Warszawa: Wydaw. Szkolne i Pedagogiczne. 